\title{
Tempo e espaço enunciam o memorável que constitui os sujeitos e as línguas no acontecimento de linguagem
}

\author{
Time and space enunciate the memorable that constitutes the subjects and the \\ languages in the event of language \\ Jocyare Souza ${ }^{1}$ \\ Universidade Vale do Rio Verde
}

\begin{abstract}
- RESUMO: Este trabalho de pesquisa apresenta, sob a perspectiva teórica da Semântica do Acontecimento de Eduardo Guimarães (2005), os efeitos de sentido da nomeação tomada como um fenômeno histórico. Considerando o funcionamento semântico-enunciativo dos nomes que constituem nosso corpus (Domínios Semânticos de Determinação - DSD), procuramos, por meio de análise dos processos de linguagem que evidenciam marcas culturais, enfocar o acontecimento enunciativo em sua historicidade, buscando evidenciar em que segmentos dessa comunidade quilombola, cuja língua oficial é a Língua Portuguesa, a ancestralidade africana se mantém. Há, dentro dessa perspectiva, uma relação da língua com um falante que se apresenta como sujeito político e social da enunciação.
\end{abstract}

- PALAVRAS-CHAVE: Semântica do Acontecimento. Domínios Semânticos de Determinação. Designação. Cultura Afro-brasileira.

- ABSTRACT: This research presents, from the theoretical perspective of the Semantics of the Event of Eduardo Guimarães (2005), the effects of meaning of the naming taken as a historical phenomenon. Considering the semantic-enunciative functioning of the names that make up our corpus (Semantic Domains of Determination - SDD), we try, through the analysis of the language processes that evidence cultural marks, to focus the enunciative event in its historicity, trying to show in which segments of that Quilombola community, whose official language is Portuguese, African ancestry remains. There is, within this perspective, a relation of language with a speaker who presents himself as a political and social subject of enunciation.

- KEYWORDs: Semantics of the Event. Semantic Domains of Determination. Designation. Afro-Brazilian culture.

\section{Considerações Iniciais e Contextualização}

O presente trabalho é resultado do projeto de pesquisa, intitulado 'QUILOMBO DA FAZENDA: os nomes enquanto relato do cotidiano de comunidade de remanescentes quilombolas' realizado no período de 02.06.2014 a 01.06.2016, em nível de pós-doutoramento, sob a condição de Pesquisador Colaborador do Instituto de Estudos da Linguagem - UNICAMP.

O projeto a que nos referimos é, de certa forma, a continuidade de um trabalho que se iniciou no mestrado (dissertação intitulada 'Nas Letras de São Thomé: uma análise semântica histórico-enunciativa dos nomes de estabelecimentos comerciais de São Thomé das Letras') quando nos propusemos a pensar os efeitos de sentido que a nomeação, tomada como um fenômeno urbano, vem produzindo em São Thomé das

\footnotetext{
${ }^{1}$ Doutora em Linguística pela UNICAMP.jocyol5@hotmail.com
} 
Letras-MG, propunha, assim, uma análise do processo constitutivo que marcava o espaço de enunciação das designações dos estabelecimentos comerciais de São Thomé das Letras, levando em consideração os procedimentos que predicavam e determinavam seu espaço semântico-enunciativo e que acabavam por marcar um lugar social do dizer, estabilizando determinados sentidos no discurso comercial/publicitário. No doutorado (tese intitulada 'Topônimos Mineiros e o Processo de Ocupação/Exploração/Formação do Estado Nacional'), os estudos pautados no processo onomástico se debruçaram sobre os efeitos de sentido da nomeação tomada como um fenômeno histórico, objetivando uma análise do processo constitutivo que marca o espaço de enunciação das designações dos nomes das cidades históricas mineiras que surgiram no Ciclo do Ouro, enfocando o acontecimento enunciativo em sua historicidade; partimos, então, do pressuposto de que a toponímia confirma, por meio de suas enunciações, o caráter de lugar central que os arraiais, as vilas e as cidades desempenhavam na região mineradora, uma vez que evidenciam no que se refere à designação dos topos - os nomes dados/não dados/renomeados - a relação do homem com o meio e com o outro.

Dessa forma, o projeto de pesquisa, intitulado 'QUILOMBO DA FAZENDA: os nomes enquanto relato do cotidiano de comunidade de remanescentes quilombolas' é a continuidade de um trabalho a que nos propusemos e pretendeu examinar a permanência de línguas africanas assim como a relação dessas com outras línguas de contato em quilombos, "espaços históricos de busca de liberdade do africano escravizado, que hoje se transformaram em comunidades quilombolas" (BRASIL, 2010, p.03).

Além do aspecto linguístico já enfocado, o presente trabalho buscou evidenciar a importância de se estudar a cultura afro-brasileira em atendimento à Lei 10.639/03, que versa sobre o ensino da história e cultura afro-brasileira e africana e ressalta a importância da cultura negra na formação da sociedade brasileira. A Lei 10.639/03 (CAVALLEIRO, 2005) propõe novas diretrizes curriculares para o estudo da história e cultura afro-brasileira e africana; os professores devem ressaltar em sala de aula a cultura afro-brasileira como constituinte e formadora da sociedade brasileira, na qual os negros são considerados como sujeitos históricos, valorizando-se, portanto, o pensamento e as ideias de importantes intelectuais negros brasileiros, a cultura (música, culinária, dança) e as religiões de matrizes africanas.

A partir do contato com o dispositivo teórico formulado pela Semântica do Acontecimento (GUIMARÃES, 2005), despertamos nosso interesse pelo processo designativo dos nomes comuns/próprios. Entendemos a importância de estudar os processos de designação urbanos e, assim, por meio da formulação de questões sobre as relações sociais urbanas, compreender a questão do nome no processo histórico e social de urbanização. Interessou-nos, particularmente, a questão da inclusão e da exclusão de cidadãos, assim como a distribuição de papéis sociais que se encontra atrelada a uma configuração enunciativa que se dá num espaço de disputa regulado pela palavra. Partimos, pois, do pressuposto de que pensar a nomeação como uma simples forma de classificação é deixar de fora uma série de fatores histórico-sociais que estão presentes na linguagem. Segundo Rancière (1994), um nome não classifica, ele identifica. Um nome, nessa concepção teórica, apresenta-se como um recorte do mundo, de forma a construir o sentido da coisa existente, o que torna a cultura um modo diferente de identificar e recortar a realidade. "Num acontecimento em que um certo nome funciona, a nomeação é recortada como memorável por temporalidades específicas" (GUIMARÃES, 2005, p.27). Não se trata, portanto, de uma relação entre um nome e uma classe de objetos no mundo, mas de um processo histórico de identificação pela 
construção do sentido que trabalha a constante redivisão do sensível que acompanha o nomear, o referir, o designar.

Dentro dessa perspectiva, propusemo-nos a compreender a circularidade com que nomes que remetem à ancestralidade africana se dá entre os habitantes da comunidade de remanescentes quilombolas do Quilombo da Fazenda. Procuramos, assim, por meio de análise dos processos de linguagem de trocas culturais, considerando o desenvolvimento constitutivo que marca o espaço de enunciação das designações que constituem nossos corpora, enfocar o acontecimento enunciativo em sua historicidade, buscando evidenciar em que segmentos da comunidade quilombola os nomes africanos se mantêm.

Nessa relação entre nomes que designam relação com uma ancestralidade africana, procuramos compreender o efeito da Mídia enquanto detentora de um certo jogo de conhecimento que institui a noção de cultura - o que é "primitivo e ou profano', o que é "civilizado e ou sagrado"? - nessas comunidades quilombolas, a fim de constatar entre as gerações mais velhas e mais novas os efeitos da indústria cultural que ao definir o que é sagrado/culto busca padronizar o sujeito consumidor.

A circularidade com que nomes que remetem à ancestralidade africana se dá entre os habitantes da comunidade de remanescentes quilombolas do Quilombo da Fazenda marca a especificidade que sempre se constitui a partir da "história em que o nome se dá como nome" (GUIMARÃES, 1992, p.16). Partimos, assim, do pressuposto de que designar é fazer significar, é produzir sentido; é considerar que o funcionamento do processo de designação são sentidos produzidos, considerando relações enunciativas e discursivas. Designar é revitalizar a memória, o pré-construído, o já dito em outro lugar que afeta o sujeito da enunciação. Interessa-nos, portanto, entender o que esse processo designativo específico, a que nos propomos analisar, recorta como memorável, uma vez que consideramos que no funcionamento semântico-enunciativo há uma especificidade no nome que está posto enquanto forma de enunciar as práticas sociais, culturais e políticas dos membros que compõem a comunidade de remanescentes quilombolas do Quilombo da Fazenda. objetivamos:

Como forma de refletir sobre os processos de construção da cultura, (em uma abrangência geral)

a) avaliar a presença de traços de línguas africanas, a partir da constatação de nomes que remetem à ancestralidade africana na comunidade de remanescentes quilombolas do Quilombo da Fazenda;

b) (em nível mais específico)

c) organizar um banco de dados histórico, linguístico e cultural - ênfase aos nomes que remetem à ancestralidade africana sobre a comunidade quilombola investigada;

d) descrever o processo designativo que enuncia a circularidade com que nomes que remetem à ancestralidade africana se dá entre os habitantes da comunidade de remanescentes quilombolas do Quilombo da Fazenda, considerando funcionamento semântico-enunciativo que apresenta os Domínios Semânticos de Determinação de nomes que constituem o corpus.

e) examinar em que segmento social a permanência de línguas/culturas africanas ênfase aos nomes que remetem à ancestralidade africana - resistem na comunidade quilombola investigada.

\section{Constituição dos Corpora: o olhar do pesquisador sobre a comunidade de remanescentes quilombolas do Quilombo da Fazenda}


Para pensar as africanidades, Silva (2003, p. 26) apresenta em "Africanidades brasileiras: esclarecendo significados e definindo procedimentos metodológicos" reflexão relevante:

\begin{abstract}
A expressão africanidades brasileiras refere-se às raízes da cultura brasileira que têm origem africana. Dizendo de outra forma queremos nos reportar ao modo de ser, de viver, de organizar suas lutas, próprio dos negros brasileiros $\mathrm{e}$, de outro lado, às marcas da cultura africana que, independentemente da origem étnica de cada brasileiro, fazem parte do seu dia a dia.
\end{abstract}

A pesquisa à qual descrevemos pautou-se por ser um estudo diacrônico da comunidade de remanescentes quilombolas do Quilombo da Fazenda, com relevância para a pesquisa quantitativa, uma vez que se estabeleceu análise comparativa para mensurar nomes que remetem à ancestralidade africana/remetem a outras ancestralidades; assim como qualitativa, uma vez que, por meio do funcionamento semântico-enunciativo que apresentam os Domínios Semânticos de Determinação, pretendemos constatar o que os nomes designam, recortam como memorável.

A abordagem à comunidade quilombola investigada considerou princípios etnográficos, a coleta de conjunto de dados que compuseram os corpora de análises foram efetuados por meio de viagens de campo, prioritariamente, para aplicação de questionários e/ou entrevistas aos membros da comunidade, tendo em vista as variáveis idade/nível de escolaridade e abordaram, a princípio, processos de nomeação que remetem ao nome de batismo/aos apelidos (renomeações), às funções sociais ligadas ao trabalho coletivo/familiar, à cultura (música, culinária, dança), ao culto de religiões de matrizes africanas, às questões pessoais como saúde/doenças/cuidados com a aparência - produtos utilizados, à toponímia local, ao reconhecimento de ferramentas ligadas à tecnologia tradicional e às novas tecnologias assim como de suas funções básicas, sobretudo àquelas associadas à produção de conhecimento; o levantamento de dados deu-se, também, por meio de pesquisa documental, tendo em vista a análise de atas, livro-caixa, ofícios, livro-tombo, procurações, cartas e afins, livros de receita.

O trabalho com os corpora considerou princípios etnológicos, a sistematização e teorização dos dados deu-se por meio de análise morfossintática e semânticoenunciativa dos nomes que o constituem. Todo o processo de pesquisa foi permeado por pesquisa bibliográfica em literatura específica à temática quilombola assim como por pesquisa à literatura científica que sustentou as análises linguísticas dos corpora.

As viagens de campo à comunidade de remanescentes quilombolas do Quilombo da Fazenda para pesquisa documental levou-nos a refletir sobre o que significa estudar a ancestralidade africana enquanto afrodescendência ligada às suas tradições culturais.

Todas as pessoas, todas as coisas e todos os lugares têm a sua parte de NTU (Força vital - Axé), na concepção Bantu do mundo. Tomando essa ideia do pensamento africano inferimos que: todas as coisas, todos os lugares e todas as pessoas possuem uma parcela de conhecimento. Assim, a nossa postura de investigação científica é a troca de conhecimento com estas pessoas e com esses lugares que são ambientes da nossa pesquisa participante. (CUNHA, Jr., 2006, p. 01)

Ao tratarmos da constituição do objeto de análise de que se propôs esse projeto de pesquisa - corpus que evidenciasse a permanência ou não de ancestralidade africana na comunidade de remanescentes quilombolas do Quilombo da Fazenda -, coletamos no período de dezembro 2015 a maio 2016 vasto acervo que inclui documentos linguísticos importantes sobre o cotidiano do Quilombo da Fazenda; todavia, em virtude 
da data de aprovação para realização da pesquisa pela Comissão Técnico-Cientifica (COTEC) do Instituto Florestal do Parque Estadual da Serra do Mar (PESM) por meio da Carta COTEC n ${ }^{0}$ 354/2015 D211/2014 PGH somente em 28 de julho de 2015 e posterior agendamento de visitação in loco a partir de dezembro 2015, consideraremos, como corpus de análise, neste Artigo, recortes textuais de um site credenciado pelo Governo Federal que divulga o cotidiano do Quilombo da Fazenda. A seguir uma mostra do site http://quilombodafazenda.org.br/ Acesso em 16.04.2014 (adaptado):

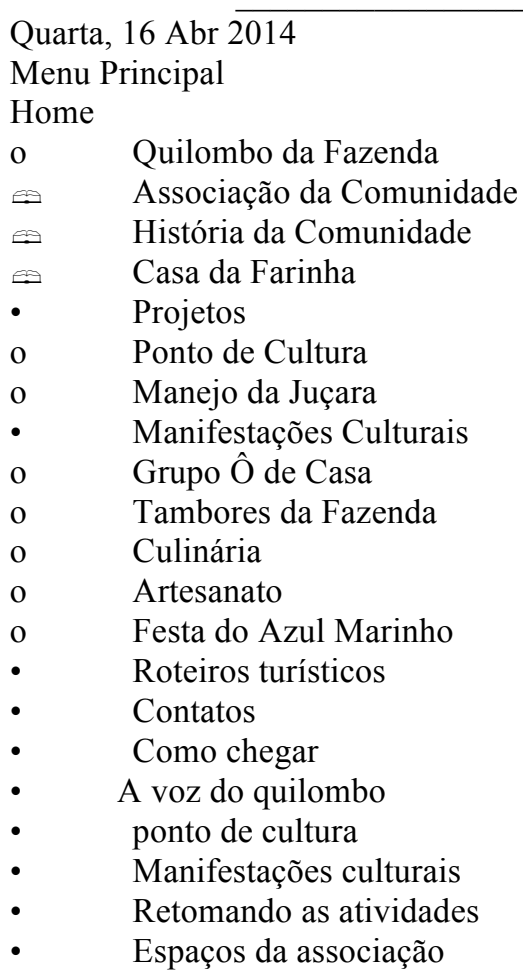

Festa de Inauguração da Casa de Artesanato Comunitária!!!!!

Escrito por Administrator

Qui, 18 de Abril de 2013 22:15

Sábado dia 16 de fevereiro recomeçaram as atividades do Ponto de Cultura Olhares de Dentro "valorizando a Memória e Fortalecendo as Raízes do Quilombo da fazenda".

No sábado as oficinas de preservação do fandango caiçara e do jongo, que inclui a confecção artesanal de instrumentos de musica (Rabeca e Viola), e no decorrer da semana as oficinas de custura e vivência musical deram inicio a mais uma etapa do longo processo de aprimoramento da cultura tradicional local.

As férias acabaram, e os interesses, as lutas e a busca pelos objetivos continuam. Isso em todo o lugar, claro, mas os aspectos de cada um desses pilares são individuais para cada grupo de pessoas. Falo assim considerando os jovens da Comunidade Quilombola da Fazenda, que depois da lida semanal na escola, mostram-se virtuosos nas atividades de Ponto de Cultura.

A Educação não formal pode atingir níveis inimagináveis dentro da sociedade, pois a descontração, a liberdade estimula a criança e o adolescente a criar, pensar e fazer tudo dentro de seus próprios limites, sem causar a sensação de obrigação, ou qualquer tipo de frustração. É como se elas estivessem em casa brincando, tendo um orientador para que essas atividades venham ser o caminho de um futuro cheio de conhecimento e perspectivas.

Saiba mais sobre:

- $\quad$ Ponto de cultura

Quilombo da Fazenda

Copyright (C) 2012 . Joomla Designed by quilombodafazenda.org.br

Fonte: http://quilombodafazenda.org.br/ Acesso em 16.04.2014 (adaptado) 
Esperamos, considerando memória enquanto prática enunciativa, evidenciar qual é a cor da cultura presente hoje na comunidade de remanescentes quilombolas do Quilombo da Fazenda. Retomamos cor da cultura enquanto expressão ora tomada como parafrástica - "A Cor da Cultura é um projeto educativo de valorização da cultura afrobrasileira que teve seu início em 2004 [...]” ora como polissêmica: a ancestralidade rememora a cultura africana? A afrodescendência está ali hoje (?), sempre esteve (?), nunca esteve (?); enquanto comunidade quilombola, entre seus membros há valores comuns que se sustentam em uma cultura singular como se enuncia no site credenciado pelo Governo Federal que divulga o cotidiano quilombola? $\mathrm{O}$ polissêmico e o parafrástico - conceitos trabalhados por Orlandi (1980); parafrástico porque sempre retoma sentidos outros (não se constitui discurso fundador) e polissêmico porque ao retomar o já dito, estabelecemos o novo: é outro discurso, outros sentidos afetados histórica e ideologicamente.

\section{Quilombo da fazenda: tempo e espaço enunciam o memorável}

Para fundamentar nossas reflexões, retomamos Achard (1999), para quem a materialidade da memória social é constituída pela própria estruturação do discurso. A memória é, dentro dessa concepção, recortada pela prática enunciativa, que se dá pela linguagem, pelos dizeres e constitui-se como todo ato de linguagem, a partir de disjunções, de conflitos e de polêmicas, que se materializam nos/pelos sentidos. $\mathrm{O}$ funcionamento da memória se dá por regularidades e deslocamentos, que a (re)constituem e a (re)organizam, (re)significando acontecimentos, a partir de outros construídos em determinadas práticas enunciativas.

Nossas primeiras observações nos fazem comungar a concepção de Cunha Jr. (2001) de que a força da comunidade está na terra em torno da qual se estabelece a sociedade e se plantam as relações sociais ao longo das condições historicamente determinadas. Buscamos, assim, entender, por meio do funcionamento enunciativo dos textos de autoria de 'Administrador', apresentados no site http://quilombodafazenda.org.br, que ora configuram nosso corpus de análise, de que forma as práticas de linguagem recortam um memorável que se institui no cotidiano de uma comunidade de remanescentes quilombolas, sociedades que se organizam considerando a ancestralidade africana que se manteve nos grupos étnicos, e de que forma valores socioculturais afrodescendentes de ancestralidade, comunidade, oralidade ali estiveram, mantêm-se, são apagados e / ou silenciados. Nossa exposição analítica priorizará o texto (na íntegra e/ou seus fragmentos) do link ‘ Quilombo da Fazenda' que se segue:

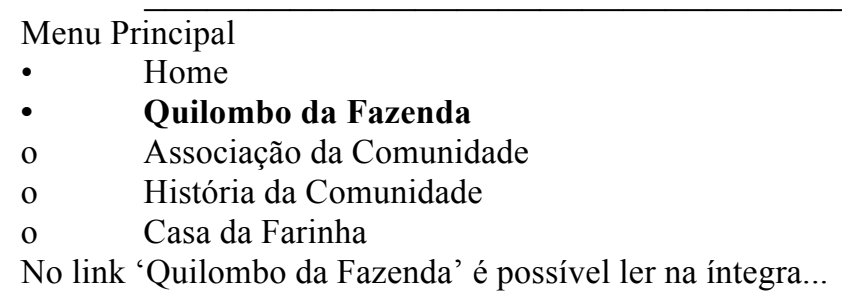

Um pouco de história do quilombo para voçê!!

A primeira notícia que se tem da "Fazenda Picinguaba (refugio de peixes - tupi guarani), remonta o final do século XIX, período em que faleceu Maria Alves de Paiva, proprietária da Fazenda”. Em 1884 ela falece e em testamento declara o desejo que seus escravos sejam libertos e que possam habitar em certas áreas da Fazenda. A Fazenda Picinguaba possuiu vários proprietários até que no ano de 1943 seu novo dono Saint Claire adquire parte da Fazenda e nomeia o Sr. Leopoldo Braga o administrador da Fazenda 
Picinguaba. Leopoldo recebe a autorização de trazer 12 famílias para trabalharem através de usufruto, sendo proibidas de vender a arrendar suas terras.

Em 1951, a Fazenda Picinguaba foi hipotecada pela Caixa Econômica do Estado de São Paulo e perdurou esse domínio até 1974 , por isso, a Fazenda Picinguaba também é conhecida como Fazenda da Caixa.

Em 1975, o trecho entre Ubatuba e Paraty (RJ) da rodovia Rio-Santos - BR 101 - foi construído e no ano de 1979 para controlar as grilagens e invasões de terra a Fazenda é anexada ao Parque Estadual da Serra do Mar.

No ano de 2005, a Fazenda Picinguaba recebeu o reconhecimento da Fundação Palmares como sendo um remanescente de quilombo.

No texto 'Quilombo da Fazenda', a noção de tempo (ancestralidade africana) está aparentemente associada à noção de espaço (Quilombo da Fazenda), logo 'tempo' e 'espaço' determinam os sentidos que vão sendo construídos, porque 'Quilombo da Fazenda' e 'ancestralidade africana' significam de acordo com as relações de determinação semântica que se constituem no acontecimento enunciativo, pelo modo como se relacionam com outras palavras no texto. Buscaremos compreender esse processo de reescritura que enuncia um memorável que recorta práticas sociais recorrentes desse 'tempo' / 'espaço'.

O nome é, dessa forma, um texto carregado de sentido; todavia não há texto sem o processo de deriva de sentidos, sem reescritura; é essa deriva enunciativa incessante que constitui, ao mesmo tempo, o sentido e o texto. $\mathrm{O}$ processo de reescritura, próprio das relações de textualidade, se apresenta, portanto, como a contemporanização do acontecimento (GUIMARÃES, 2002).

Considerando o funcionamento enunciativo e as relações que se estabelecem por meio do Domínio Semântico de Determinação (DSD), buscaremos evidenciar nas reescrituras de 'tempo' / 'espaço' o sentido que se recorta como memorável.

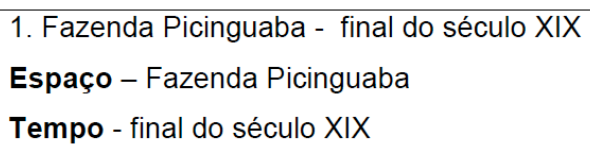

Podemos definir como DSD

- O nome fazenda articula pelo recurso de substituição o nome sesmaria (área de terra doada às pessoas para cultivo).

- O nome fazenda estabelece com sesmaria uma relação de sinonímia.

- O nome Picinguaba determina pelo recurso de definição o nome Fazenda.

- O nome Picinguaba (do tupi guarani) reeescritura 'refúgio de peixes' e institui ao relacionar-se com o nome Fazenda o efeito de especificação.

Assim, o tempo definido como final do século XIX, tomado como ancestralidade, enuncia a presença de sesmários, no caso Maria Alves de Paiva, e de caiçaras. Maria Alves de Paiva é, conforme determinação do Diário Oficial da União herdeira de uma sesmaria ${ }^{2}$.

O espaço (Fazenda Picinguaba) está determinado pelo tempo (século XIX) que recorta como memorável uma ancestralidade indígena, o nome Picinguaba enuncia a presença do indígena, o que de certa forma influencia a nomeação da fazenda. $\mathrm{O}$ processo de nomeação da fazenda enuncia a presença da cultura caiçara assim como sua

\footnotetext{
2 Documento Oficial disponível na íntegra em http://www.jusbrasil.com.br/diarios/1890305/pg-21-secao-1-diariooficial-da-uniao-dou-de-26-11-1916
} 
estreita relação com a pesca, prática social que influencia a nomeação da fazenda. A ancestralidade indígena é, dessa forma, anterior, à ancestralidade africana.

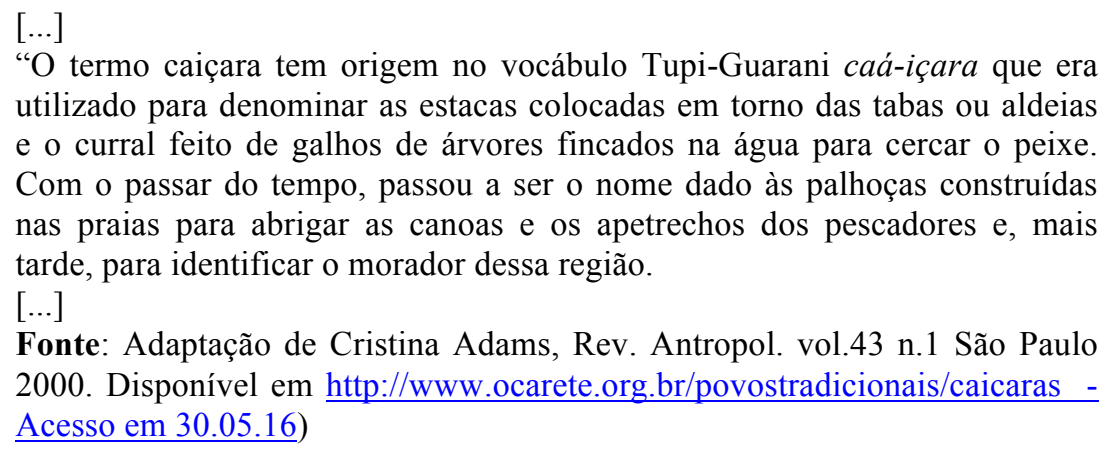

A ancestralidade indígena é, dessa forma, anterior à ancestralidade africana. Tempo (Final do século XIX) / Espaço (Fazenda Picinguaba) enunciam o apagamento do Quilombo da Fazenda e de uma ancestralidade africana.

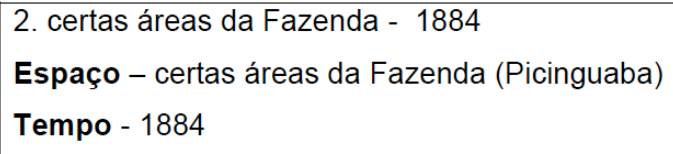

Podemos definir como DSD

- O nome fazenda reescritura pelo recurso de condensação Fazenda Picinguaba.

- O nome fazenda estabelece uma relação de anáfora com Fazenda Picinguaba.

- O nome fazenda estabelece com Fazenda Picinguaba uma relação de sinonímia.

- Em certas áreas da Fazenda, 'certas áreas' funciona como elemento catafórico.

Assim, o tempo definido como 1884, tomado como ancestralidade, enuncia a presença de sesmários, descendentes de Da. Maria Alves de Paiva, de caiçaras e de negros que serão libertos. A expressão 'Negros que serão libertos', anaforicamente, enuncia por substituição a existência de 'negros escravos'. Certas áreas da Fazenda enuncia um espaço ressignificado da Fazenda Picinguaba, uma vez que já se institui o espaço que será demarcado como área quilombola. Certas áreas da Fazenda, sob efeito de especificação, enuncia que existirão certas áreas que significarão diferentemente enquanto área de escravos libertos, o que evidencia um deslocamento de sentido para quilombo, que tem sua origem na língua banta e significava, inicialmente, acampamento ou fortaleza; a palavra foi usada pelos portugueses para denominar as povoações construídas por escravos fugidos que se rebelaram contra a ordem escravista (LEITE, 1999).

A expressão Fazenda Picinguaba, nessa concepção, passa a funcionar, sob o efeito de totalização, como hiperonímia; a Fazenda é as 'certas terras' (o quilombo) e 'as demais terras'.

O Tempo (1884) / Espaço (Fazenda Picinguaba) rememoram uma ancestralidade africana e enunciam a presença de negros nesse espaço geográfico negros que ainda são escravos e que devem ser libertos - o quilombo que se enuncia em 1884, como 'certas áreas da Fazenda Picinguaba, será um espaço de negros libertos. 'Certas áreas' enuncia que em outras áreas não demarcadas existiam outras presenças, sobretudo, a do caiçara que já convive nesse espaço geográfico com o negro. Logo a Fazenda (Picinguaba) é um espaço que enuncia uma ancestralidade marcada pelo convívio de negros, caiçaras e sesmeiros descendentes de Da. Maria Alves de Paiva. 


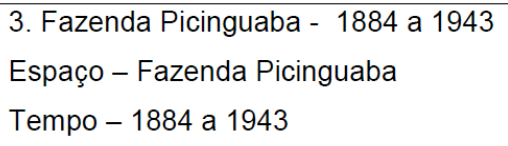

Podemos definir como DSD

- O nome Fazenda Picinguaba (tempo: 1884 a 1943), por repetição, estabelece uma relação anafórica com Fazenda Picinguaba (tempo: final do século XIX).

Fazenda Picinguaba (tempo: 1884 a 1943) funciona, por repetição, como reescritura de Fazenda Picinguaba (tempo: final do séc. XIX) e enuncia, em uma relação de sinonímia, o memorável que faz significar Fazenda Picinguaba. O tempo (1884 a 1943) determina, sob o efeito de totalização, o espaço (Fazenda Picinguaba); não se enuncia mais as 'certas partes' que se tornariam área quilombola, mas um espaço que se institui como sendo de vários proprietários, logo de várias ancestralidades. $\mathrm{O}$ nome 'proprietários', sob efeito de generalização, reescritura Maria Alves de Paiva, sesméria 'proprietária', e enuncia um apagamento da concessão de 'certas terras', logo da demarcação de área quilombola, logo do direito concedido aos negros libertos de ocupação de determinada área da Fazenda Picinguaba. Tempo (1884 a 1943) / Espaço (Fazenda Picinguaba) enunciam o silenciamento do Quilombo da Fazenda e de uma ancestralidade africana.

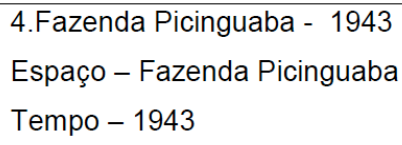

Podemos definir como DSD

- O nome Fazenda Picinguaba (tempo: 1943), por repetição, estabelece uma relação anafórica com Fazenda Picinguaba (tempo: final do século XIX)

Fazenda Picinguaba (tempo: 1943) funciona, por repetição, como reescritura de Fazenda Picinguaba (tempo: final do séc. XIX) e enuncia, em uma relação de sinonímia, o memorável que faz significar Fazenda Picinguaba. Os nomes Maria Alves de Paiva e Saint' Claire predicam diferentemente este espaço. Em ambos o nome Fazenda Picinguaba funciona hiperonimicamente: Maria Alves de Paiva enuncia a concessão de 'certas terras' que reescritura, em uma relação de sinonímia, 'área de quilombo'; Saint' Claire enuncia a concessão de 'parte da fazenda' que reescritura, em uma relação de sinonímia, 'área de imigração'. Tempo (1943) / Espaço (Fazenda Picinguaba) enunciam a presença de imigrantes e o silenciamento do Quilombo da Fazenda e de uma ancestralidade africana.

Os nomes Saint' Claire (nome originário da França) e Braga (sobrenome de origem portuguesa) marcam respectivamente o processo de colonização do Brasil. $\mathrm{O}$ espaço (Fazenda Picinguada) está determinado por uma temporalidade que enuncia a ocupação do território nacional: 12 famílias quaisquer são trazidas para trabalhar na fazenda. $\mathrm{O}$ espaço enuncia nessa temporalidade a presença de imigrantes, logo nesse espaço convivem ancestralidades diversas: dos escravos libertos por Maria Alves de Paiva, dos caiçaras, dos imigrantes (italianos?), dos portugueses, dos franceses.

\section{Considerações Finais}


Nossas análises nos levaram a concluir que o sujeito se constitui na e pela linguagem e que "num acontecimento em que um certo nome funciona, a nomeação é recortada como memorável por temporalidades específicas" (RANCIÈRE, 1992, p.27,); assim, uma palavra não inaugura o sentido em si, mas, num passado recortado no presente da enunciação, (re)significa a sua memória e (re)toma sentidos, a partir de sua história de enunciações (GUIMARÃES, 2007). Há relações históricas, sociais, políticas e ideológicas no acontecimento, as quais afetam os sentidos daquilo que dizemos, fazendo com que eles não sejam apenas um ou qualquer um. Há uma relação de poder da língua que afeta a formulação, a circulação e a interpretação dos textos. A isso se incluem o contexto histórico, social e ideológico, os sujeitos envolvidos na enunciação, o dizer, a memória discursiva, a retomada de sentidos, a língua:

\begin{abstract}
O sentido não está, simplesmente, nas palavras, nas frases, nos segmentos linguísticos. Mas também não está nas situações em que estas palavras são ditas. A significação diz respeito a uma relação das palavras, das frases com o acontecimento (considerado sócio- historicamente) em que ocorrem, de tal modo que um enunciado não significa qualquer coisa, nem uma só coisa (GUIMARÃES, 2006, p. 126).
\end{abstract}

Só é possível pensarmos as questões de significação a partir do DSD se considerarmos o sentido em sua historicidade, com suas condições de produção, ou seja, considerando, além das relações das palavras nos textos em que aparecem, os fatores externos à sua formulação, como o interdiscurso, a ideologia, os locutores.

As palavras significam, segundo Guimarães (2007), de acordo com as relações de determinação semântica que se constituem no acontecimento enunciativo, pelo modo como se relacionam com outras no texto. É por isso que pensar o DSD, por essa Semântica, é considerar o sentido construído na enunciação, historicamente. Para o autor, esse movimento de predicação na duração do presente do memorável significa porque projeta um futuro, o tempo da interpretação no depois do acontecimento no qual o reescriturado é refeito pelo reescriturante.

Consideramos, no funcionamento enunciativo do texto 'Quilombo da Fazenda', o sentido instituído pelo binômio 'tempo' / 'espaço' construído na enunciação, historicamente. Tempo e espaço constroem-se a partir do estabelecimento das relações sociais, ao longo das condições sócio históricas determinadas. O espaço determina a condição da comunidade que se estabeleceu em espaços geográficos ancorados na crença de uma ancestralidade africana para construir sua história.

A comunidade, seus membros e as relações estabelecidas são produtoras e produzidas da/na história. A memória da comunidade ganha relevância no tempo e no espaço - os princípios de socialização das culturas africanas, a ancestralidade, a oralidade, a comunidade. O discurso recorta um memorável que se associa à posse do território por negros um direito; direito que se institui como forma de acerto de uma dívida histórica que enunciam as relações históricas e sociais construídas no passado, no presente (marcas do tempo).

Tempo e espaço enunciam as experiências de busca de conhecimento aprofundado sobre realidades vividas do reconhecimento e do conhecimento de um pensamento de base africana. As narrativas se referem a um lugar (determina ancestralidade) em um determinado tempo (determina comunidade). Valores sociais que remetem à noção de ancestralidade (marcas do tempo) e comunidade (marcas de espaço). A ancestralidade (ora africana, ora caiçara, de outrem) enuncia a construção do lugar, do território dado, pelo acúmulo repetitivo da experiência humana. A 
ancestralidade define os parâmetros para compreensão da história de uma comunidade que se institui em determinado tempo/lugar.

A necessidade do caráter histórico do espaço socialmente construído, o lugar. A comunidade é vista como a força da identidade pela via da ancestralidade. Tempo, lugar, ancestralidade, comunidade enunciam o pertencimento / a posse da terra como forma de diferenciação para exigirem a garantia de direitos e cidadania, lugar de negociação com o poder público.

\section{REFERÊNCIAS}

ACHARD, Pierre. Memória e produção discursiva do sentido. In: memória. Tradução José Horta Nunes. Campinas: Pontes, 1999, p. 11 - 21. et al. Papel da

BERNADINO, J.; GALDINO, D. (Org.). Levando a raça a sério: ação afirmativa e universidade. Rio de Janeiro: DP\&A Editora, 2004.

BRASIL, Ministério do Desenvolvimento Social e Combate à Fome. Guia de cadastramento de famílias quilombolas. $2^{\mathrm{a}}$ ed. Brasília: MDS, 2010.

CAVALLEIRO, E. Educação antirracista: caminhos abertos pela Lei Federal 10.639/03. Brasília: Coleção Educação para Todos, 2005.

CUNHA JR, Henrique. Africanidade, Afrodescendência e Educação. Educação em Debate, Fortaleza, Ano 23, vol. 2, nº 42, 2001.

GUIMARÃES, E. (2002-a) Texto e Argumentação. $3^{\text {a }}$ ed. Campinas: Pontes, 1987.

GUIMARÃES, E. Terra de Vera Cruz, Brasil. Rio de Janeiro: Cultura Vozes - 4, 1992.

GUIMARÃES, E. Os limites do sentido. Campinas: Pontes, 1995.

GUIMARÃES, E. Um Mapa e suas Ruas. DL/IEL/LABEURB - UNICAMP Campinas, 1999.

GUIMARÃES, E. Semântica do Acontecimento. $2^{\circ}$ Edição. Ed.Pontes, 2005.

GUIMARÃES, Eduardo. Domínio Semântico de Determinação. In: GUIMARÃES, Eduardo; MOLLICA, Maria Cecília (orgs). A palavra: forma e sentido. Campinas: Pontes Editores; RG Editores, 2007. p. 77-96.

GUIMARÃES, Eduardo. A enumeração: funcionamento enunciativo e sentido. Caderno de Estudos Linguísticos, 51. v. 1. Campinas: Unicamp. Jan./Jun. 2009. p. 4968.

LEITE, Ilka Boaventura et alli. Quilombos e quilombolas: cidadania ou folclorização? Horizontes Antropológicos, Porto Alegre, ano 5, n. 10, p. 123-150, maio de 1999.

ORLANDI, E P. O discurso pedagógico: a circularidade. Estudos Lingüísticos. p.157-169, 1980.

ORLANDI, E P. Interpretação; autoria, leitura e efeitos do trabalho simbólico. Rio de Janeiro: Vozes, 1996.

ORLANDI, E P. Análise de Discurso: Princípios e Procedimentos. Campinas: Pontes, 1999. 
PROGRAMA BRASIL QUILOMBOLA. Comunidades Quilombolas Brasileiras. Regularização Fundiária e Políticas Públicas. Presidência da República/Secretaria Especial de Promoção da Igualdade Racial/Subsecretaria de Políticas para Comunidades Tradicionais. 2010.

QUEIROZ, D.M. O ensino superior no Brasil e as ações afirmativas para negros. Universidade \& Sociedade, Brasília, DF, v. 12, n. 29, 2003.

RANCIÈRE, J. Os Nomes da História. Campinas, Pontes/ Educ, 1994.

SILVA, P. B. G. Africanidades brasileiras: esclarecendo significados e definindo procedimentos metodológicos. In: Revista do Professor, 9 (73), p.26-30, jan./mar. 2003.

Disponível em: <http://www.revistadoprofessor.com.br/system/ biblioteca /materias /AFRICANIDADE . pdf>. Acesso em: 18 mai. 2016.

STRANGELOVE, M. As muralhas estão caindo. Rio de Janeiro: Internet World, 1995.

Recebido em: junho de 2017.

Aprovado em: julho de 2017.

Como citar este trabalho:

SOUZA, J. Tempo e espaço enunciam o memorável que constitui os sujeitos e as línguas no acontecimento de linguagem. Traços de linguagem, v. 1, n. 1, p. 45-56, 2017. 